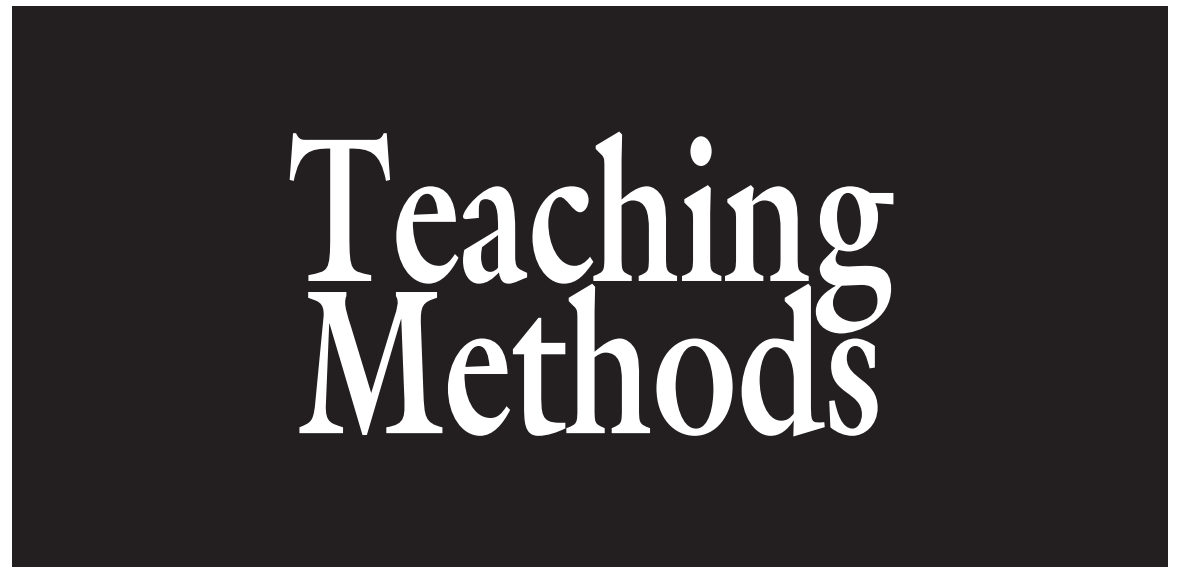

\title{
Experiential Learning Enhances Student Knowledge Retention in the Plant Sciences
}

\author{
Taryn L. Bauerle ${ }^{1}$ and Travis D. Park
}

AdDITIONAL INDEX WORDs. undergraduate education, informal learning, teaching practice

SUMMARY. Experiential learning can be an important part of an undergraduate curriculum in the sciences. A new course, The Nature of Plants, was developed to provide students across a broad range of majors with an in-depth study of plant science both basic and applied. The course was enriched by using a local natural area as an informal learning environment. We examined whether experiential learning improved homework scores among students who participated in a field trip by asking if simply attending the field trip increased the homework score or if participation in the tree climbing exercise had any additional benefit. Our results show participating in a field trip experience when coupled with a homework assignment increased student homework scores. Moreover, the tree climbing portion of the field trip increased homework scores particularly for students not in a science major. This research supports experiential learning and the value of field trips within science courses focused on a comprehensive exploration of plants.

S

tudies in plant sciences are grounded in concepts aimed to acquaint students with nature through experiential learning. Unfortunately, these concepts easily become diluted in traditional lecture and laboratory-based courses often disconnected from the natural environment. In addressing the need for transforming agricultural education in a changing world, the National Research Council (2009) posited "many classes fail to engage students or to take advantage of the research in how people learn." Further, the National Research Council recommended college faculty in agriculture to collaborate

Department of Horticulture, Cornell University, 134A Plant Science Building, Ithaca, NY 14853

We thank Mark Holton and the tree climbing staff at Cornell Outdoor Education for their time and expertise. Class materials and field trip gear were provided by the Cornell Office of Academic Programs.

${ }^{1}$ Corresponding author. E-mail: bauerle@cornell.edu. and offer multidisciplinary courses engaging students in the complexity of problem-solving and critical thinking inherent in addressing agriculture and natural resource issues. Understandably, many undergraduate courses are taught by professors or instructors with expertise only within an individual range of content area. An experiential approach to course instruction provides an otherwise be unachievable additive component to the learning process (Spelt et al., 2009).

Experiential learning is founded in the work of Dewey (1938), Lewin (1951), Piaget and Inhelder (1969), and (Kolb 1984; Kolb et al., 2001), whereby learning is initiated in the works of an interaction between the learner and his or her environment. Specifically, Kolb described learning as the transformation of knowledge from experiences. Dewey suggested all experiences are not equally educative with some being more engaging from cognitive, emotional, and physical standpoints. Field trips, especially the ones described in this article, tap student's cognitive, emotional, and physical faculties. Lewin theorized that learning is a continuous cycle whereby learning arising out of concrete experiences is then transformed through observation and reflection to give rise to generalizations about phenomena, as well as to develop abstract conceptualizations about future events or experiences.

New shifts in undergraduate education favor implementation of digital learning tools including online interactive tools and multimedia (Campbell et al., 2011). While we do not discount those resources as viable and even valuable for undergraduate education, integration of field trips and related concrete learning experiences into course curricula has been shown to increase student involvement and therefore retention of course material (Dillon et al., 2006). Field trips have been a part of undergraduate curriculum in the plant sciences for decades. Informal learning settings offered through field trips have been shown to qualify learning experiences by making them more rewarding to students prone to further self-driven inquiry, and longer retention of material and experiences (Anderson and Piscitelli, 2002). Moreover, an even stronger learning effect results from postvisit exercises such as homework assignments (Anderson et al., 2000).

Place-based education builds upon the foundation of experiential learning by grounding learning in the local community and environment, oftentimes through the use of field trips (Sobel, 2005). In place-based education, field trips are not just a visit-andobserve activity, but rather engaging, stimulating, educative experiences. The use of place-based education and field trips have demonstrated gains in achievement (Bartosh et al., 2006), improved critical thinking and problemsolving (Ernst and Monroe, 2006), and increased engagement with learning (Emekauwa, 2004; Lieberman and Hoody, 1998).

A recent reorganization of the undergraduate biology curriculum within the Cornell Office of Undergraduate Biology has resulted in a larger pool of courses to satisfy the biology distribution requirement for 
students in the biological sciences, life sciences, and non-life science majors. In an effort to serve the students enrolled in the Plant Science major and closely related majors, a faculty member in the Department of Horticulture teamed with the Cornell Outdoor Education (COE) program to develop an introductory course aimed at developing a multidisciplinary educational team to encourage individuals from multiple disciplines to contribute a particular expertise enabling new and novel ways to present course material. The Nature of Plants (HORT 1115) was developed to provide students with the background necessary to begin an in-depth study of plant science both basic and applied, and to enrich the course with an informal learning environment at a local natural area.

The course presented an interesting challenge because of the diverse representation of students from across campus. Several students were not plant science majors and some had little to no background in understanding the nature of plants. The objective of this classroom action research analysis was to determine the impact of a tree-climbing field trip experience on student learning in the course. Specific objectives were to determine whether the experiential learning exercise would improve student performance on homework assignments and to determine whether students participating in a more active experiential exercise would demonstrate improved performance on homework assignments.

One of the prevailing goals of this course was to learn how to think about plants and ecosystems, especially from an experiential, scientific perspective. Ecosystems are far more complex than they appear as diagrams in a textbook or in lecture discussions. Therefore, focusing the major objective of incorporating several concepts from the course, a large homework project was incorporated into the course. For example, the major concepts from the course included plant species diversity, succession, and plant dominance. Each of these course teaching concepts is not particularly novel in their own right; however, when explored in concert from a multidisciplinary perspective, they do take on added complexity and uniqueness.

When the course instruction is coupled with a hands-on activity, the limit of a traditional course field trip is stretched toward a new level of student experience. The faculty member developed a homework assignment to accompany the field trip exercise and to be completed individually by students. The homework assignment included on-the-ground questions and measurements concerning environmental parameters, plant development, and community structure.

In an effort to facilitate course learning and provide students with a new format for information acquisition, $\mathrm{COE}$ augmented the course with tree climbing instruction. $\mathrm{COE}$ uses their expertise in tree climbing to introduce students to climbing safety and practices at the Lindseth climbing wall on the Cornell campus during the semester, and then guides the students through two climbing exercises in mature trees for the class homework project at the end of the semester.

\section{Methods}

The research methods in this study were classroom action research in nature. McNiff (1988) explained action research as research informing teaching practice through reflection in and on practice, in the service of improving the educative experiences of students. Action research in higher education has taken on new prominence in the development of the scholarship of teaching and learning. Examples of action research are prevalent (i.e., Walser, 2009). The nature of such research is when a professor or teacher observes a phenomenon in his or her classroom, and then gathers data to determine the effectiveness of the phenomenon on some variable of interest or importance. In this research, through analysis of data and reflection on the learning experience, we attempted to determine if the experience of engaging with tree canopies had an effect on the content learning in the course.

Reflection on practice is a key aspect of classroom action research (Mertler, 2009). Schon (1984) would describe this as "reflection-on-action," or reflection occurring after an event, as opposed to "reflection-in-action," reflection occurring in the moment of the event or in the moment of teaching practice. The course instructor and coauthor of this article have reflected on the effectiveness of the course experiences when analyzing the evidence for its effectiveness. The research outline followed Mettetal's (2001) steps for action research.

COURSE PROFILE AND LEARNING ACtivities. Seventy undergraduate students enrolled in HORT 1115. The population of students enrolled in the course represented four different colleges/schools and 17 distinct majors within Cornell, College of Arts and Sciences, College of Agriculture and Life Sciences, School of Hotel Administration and College of Architecture, Art and Planning; majors, included, Agricultural Science, Animal Science, Arts and Sciences, Communication, Economics, Education, Food Science, and Landscape Architecture. The faculty course instructor was responsible for the majority of the course content which spanned three major categories, 1) plants and their environment, 2) plant eco-physiology, and 3) global patterns and processes. Three individual homework assignments were given during the progression of the semester. The first two homework assignments did not contain an accompanying experiential component, while the last homework assignment did. All three homework assignments required consisted of subjective questions requiring short paragraph style responses and were deemed of similar difficulty by the instructor. Students had the same amount of out-of-class time to complete all three assignments. In all fairness, the homework assignment accompanying the experiential learning exercise could have been perceived as slightly more difficult because of the inclusion of several concepts discussed throughout the semester long course. Grading for the three homework assignments were based off of a rubric that largely focused on the student demonstrating accurate understanding of the question and evidence to support the student's answer. We compared student homework scores using a Mann-Whitney nonparametric test because of lack of normality in the data set to determine if out-of-classroom, hands-on learning exercises increased homework scores.

The climbing exercises included a multidirectional zip line through a disturbed site, encroached by primary successors, and a $50-\mathrm{ft}(15.2 \mathrm{~m})$-high platform in the middle of an "oldgrowth," relatively undisturbed, oak (Quercus sp.) stand. A third site 
composed of a planted monoculture of spruce (Picea sp.) trees was also included in the field trip although no climbing took place at this location. The climbing experience served a dual purpose: 1) it allowed students to become extremely engaged in the field trip experience and 2 ) it provided students with a new bird's-eye view of the environment under question. While the field trip was required for the course, the tree climbing experience was optional. We compared homework scores within this homework assignment to determine if participating in an additional participatory exercise during the field trip affected students' homework scores.

At the start of the field trip, students were randomly assembled into groups of about five students.
While on the field trip, students gathered data for a homework assignment including several short answer and essay questions aimed at testing the students' perception of the field sites visited and the ability to formulate scientific hypothesis around their perceptions. The homework assignment was due 1 week after the field trip to allow for a more formal presentation of the work.

\section{Results and discussion}

Within the course, The Nature of Plants, 66 out of 68 students attended the field trip. Students who participated in the multidisciplinary field trip performed an average of $12 \%$ $(P<0.001)$ better on their accompanying homework assignment when compared with two previous homework

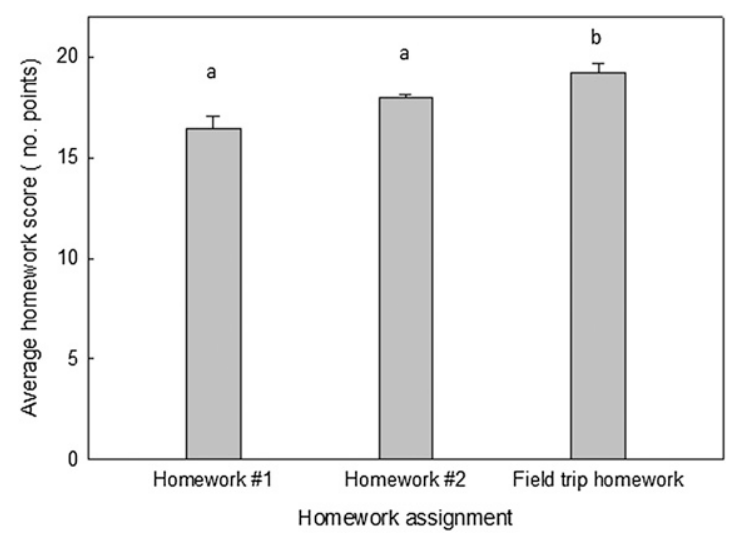

Fig. 1. Student average homework scores (out of 20 points \pm SD) for three homework assignments during the Spring 2011 semester in an introductory course, The Nature of Plants (HORT 1115), at Cornell University. Homework \#1 and homework \#2 did not include an experiential learning component adjoining the assignments, while the field trip homework included a tree climbing exercise and on-the-ground measurements as part of the assignment.

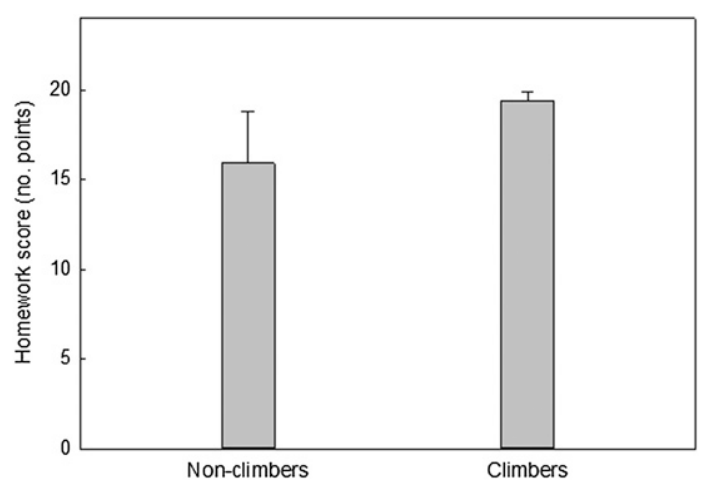

Fig. 2. Student average homework scores (out of 20 points $\pm \mathrm{SD}$ ) for the students that did not participate in an experiential learning exercise during a field trip (nonclimbers) and the students that participated in the exercise (climbers) in an introductory course, The Nature of Plants (HORT 1115), during the Spring 2011 semester at Cornell University. Differences between the two groups were significant $(P=0.002)$. assignments that did not include an informal learning environment (Fig. 1). Moreover, 51 students participated in the climbing exercise, while 15 students attended the field trip but did not participate in the climbing exercise. Participating in the tree climbing portion of the field trip increased homework scores by 19\% compared with nonclimbing students across all majors $(P=0.002)$ (Fig. 2). Arts majors showed the greatest increase in scores $(30 \%)$ than students from Plant Science or other science backgrounds and majors. Interestingly, within the group of nonclimbers, none of the students were Plant Science majors. Instead, nonclimbers were comprised of a random sampling of other majors, including, Agricultural Science (27\%), Animal Science (13\%), Arts and Sciences (13\%), Communication (13\%), Economics (7\%), Education (7\%), Food Science (7\%), and Landscape Architecture (13\%).

As further evidence of the efficacy of the tree climbing experience, students noted positive affirmations of the experience on their end-ofcourse evaluations. For example, one student noted, "The tree climbing field trip was a great idea and a lot of fun. I think the information I learned in your course, while it's not directly applicable for my intended career path, will stick with me for quite some time."

Research on learning has demonstrated associating scientific theory with productive emotional or sensory reactions including surprise and awe improve the chances of involving a larger pool of participants and encouraging their capability to learn (Bell et al., 2009). This research, although presently limited in scope, demonstrates multidisciplinary instruction within a course can positively affect student performance outcomes. While the multidisciplinary nature of our specific course example combines a formal classroom curriculum with the additional skills of tree climbing, the complementary interaction promotes a more favorable learning environment and higher student achievement than lectures and reading alone.

This research contributes to our growing literature base supporting experiential learning and the value of field trips, even when teaching relatively complex subject matter, such as the nature of plants. Students benefit from the hands-on, minds-on application of 
conceptual learning not only in terms of achievement but also in terms of effective engagement with the content.

Multiple opportunities exist for future implementation of experiential learning in the plant sciences. We show here including a field experience in an undergraduate plant science course improved student achievement and engagement. Because university professors in horticultural sciences often teach courses once per year and with relatively limited enrollments, true experimental designs are difficult, if not impossible, to conduct. True random assignment of students to course sections, and thus treatments and controls are impossible at our institution with this course. Thus, classroom action research was a rigorous and practical means of assessing the viability of a learning experience or intervention. Because we realize the significant investment of time and financial resources in field trips, it is in the best interests of individual faculty members to measure and monitor the impact of field trips and experiential learning opportunities on measure of student achievement. The end must justify the means and resources necessary to provide such experiences.

\section{Literature cited}

Anderson, D., K.B. Lucas, I.S. Ginns, and L.D. Dierking. 2000. Development of knowledge about electricity and magnetism during a visit to a science museum and related post-visit activities. Sci. Educ. 84(5):658-679.

Anderson, D. and B. Piscitelli. 2002. Parental recollections of childhood museum visits. Museum Natl. 10(4):26-27.
Bartosh, O., J. Mayer-Smith, and L. Peterat. 2006. Informal science learning on the farm: Teachers' and students' experiences in a long-term environmental education project. National Association for Research in Science Teaching, San Francisco, CA.

Bell, P., B. Lewenstein, A.W. Shouse, and M.A. Feder (eds.). 2009. Science learning in designed settings, p. 127-172. In: Learning science in informal environments: People, places, and pursuits. National Academies Press, Washington, DC.

Campbell, K.R., S.B. Wilson, P.C. Wilson, and Z. He. 2011. Interactive online tools for teaching plant identification. HortTechnology 21(4):504-508.

Dewey, J. 1938. Experience and education. Macmillan, New York.

Dillon, J., M. Rickinson, K. Teamey, M. Morris, M.Y. Choi, D. Sanders, and P. Benefield. 2006. The value of outdoor learning: Evidence from research in the UK and elsewhere. Sch. Sci. Rev. 87(320): $107-111$.

Emekauwa, E. 2004. The case for placebased: They remember what they touch. the impact of place-based learning in East Feliciana parish. Rural School and Community Trust, Arlington, VA.

Ernst, A.J. and M. Monroe. 2006. The effects of environment-based education on students' critical thinking skills and disposition toward critical thinking. Environ. Educ. Res. 12(3-4):429-443.

Kolb, D. 1984. Experiential learning: Experience as the source of learning and development. Prentice Hall, Englewood Cliffs, NJ.

Kolb, D., R.E. Boyatzis, and C. Mainemelis. 2001. Experiential learning theory: Previous research and new directions, p. 193-210. In R. Sternberg and L. Zhang (eds.). Perspec- tives on cognitive, learning, and thinking styles. L. Erlbaum Assoc., Mahwah, NJ.

Lewin, K. 1951. Field theory in social science: Selected theoretical papers. Harper, New York.

Lieberman, G.A. and L.L. Hoody. 1998. Closing the achievement gap: Using the environment as an integrating context for learning. Science Wizards, Poway, CA.

McNiff, J. 1988. Action research: Principles and practice. Routledge, London.

Mertler, C.A. 2009. Action research: Teachers as researchers in the classroom. 2nd ed. Sage, Thousand Oaks, CA.

Mettetal, G. 2001. The what, why and how of classroom action research. J. Scholarship Teaching Learning 2(1):6-13.

National Research Council. 2009. Transforming agricultural education for a changing world. 29 June 2012. <http://www. nap.edu/catalog/12602.html>.

Piaget, J. and B. Inhelder. 1969. The psychology of the child. Basic Books, New York.

Schon, D.A. 1984. The reflective practitioner: How professionals think in action. Basic Books, New York.

Sobel, D. 2005. Place-based education: Connecting classrooms and communities. Orion Society, Great Barrington, MA.

Spelt, E.J.H., J.A. Biemans, H. Tobi, P.A. Luning, and M. Mulder. 2009. Teaching and learning in interdisciplinary higher education: A systematic review. Educ. Psychol. Rev. 21(4):365-378.

Walser, T.M. 2009. An action research study of student self-assessment in higher education. Innovative High. Educ. 34(5): 299-306. 